\title{
INDÚSTRIA CRIATIVA E JORNALISMO: UMA ANÁLISE DOS PORTAIS DIÁRIO ONLINE E O LIBERAL NOS SMARTPHONES
}

\author{
CREATIVE INDUSTRY AND JOURNALISM: AN ANALYSIS OF THE \\ DIÁRIO ONLINE AND O LIBERAL PORTALS ON SMARTPHONES
}

\section{Giovanna Figueiredo de Abreu}

Mestra em Comunicação, Linguagens e Cultura pela Universidade da Amazônia (Belém/Brasil).

E-mail: giovannamfigueiredo@gmail.com

\section{Maíra Evangelista de Sousa}

Doutora em Comunicação e Informação pela Universidade Federal do Rio Grande do Sul (Porto Alegre/ Brasil). Professora do

Programa de Pós-Graduação em Comunicação, Linguagens e Cultura da Universidade da Amazônia (Belém/Brasil).

E-mail: maira.evangelistadesousa@gmail.com 


\section{Brazilian

\section{RESUMO}

Os smartphones têm se configurado como espaços para a produção de conteúdos inovadores pela indústria criativa (BELOCHIO; FEITOSA, 2018). Nesse cenário, este artigo tem o objetivo de identificar, com foco na indústria criativa, de que forma os portais jornalísticos - Diário Online (Dol) e O Liberal - têm produzido conteúdos para os smartphones. De abordagem qualitativa, a pesquisa utilizou como metodologia a análise de conteúdo (CHIZZOTTI, 2000; BARDIN, 2006). As versões móveis dos portais foram avaliadas a partir de dez categorias: usabilidade, multimidialidade, hipertextualidade, participação, modelo de negócio, design responsivo, tactilidade, nivelabilidade, personalização e multisuporte. Verificou-se que os portais jornalísticos analisados não apresentam todas as potencialidades oferecidas pelos smartphones, existindo aspectos subutilizados que precisam ser melhor explorados.

Palavras-chave: Indústria Criativa. Jornalismo. Smartphones.

\section{ABSTRACT}

Smartphones have been configured as spaces for the production of innovative content by the creative industry (BELOCHIO; FEITOSA, 2018). In this scenario, this article aims to identify, with a focus on the creative industry, how journalistic portals - Diário Online (Dol)and O Liberal - have been producing content for smartphones. With a qualitative approach, the research used content analysis as a methodology (CHIZZOTTI, 2000; BARDIN, 2006). The mobile versions of the portals were evaluated from ten categories: usability, multimediality, hypertextuality, participation, business model, responsive design, tactility, levelability, personalization and multisupport. It was found that the analyzed journalistic portals do not have all the potential offered by smartphones, there are underutilized aspects that need to be better explored.

Keywords: Creative Industry. Journalism. Smartphones. 


\section{Brazilian

\section{INTRODUÇão}

Os dispositivos digitais e, em especial, os smartphones podem ser entendidos como novos espaços para produção de conteúdo pela indústria criativa (BELOCHIO; FEITOSA, 2018). Em um cenário de convergência jornalística (BARBOSA, 2009; KOLODZY, 2009; SALAVERRÍA; AVILÉS; MASIP, 2010), cada vez mais as tradicionais empresas jornalísticas têm investido em produtos inovadores e criativos.

Este artigo tem o objetivo de identificar, com foco na indústria criativa, de que forma os portais jornalísticos - Diário Online (Dol) ${ }^{1}$ e 0 Liberal $^{2}$ - têm produzido conteúdos para os smartphones. Os portais jornalísticos analisados estão sediados em uma das metrópoles da Amazônia, a capital paraense Belém (PA). Ambos os produtos são oriundos de empresas noticiosas de tradição impressa.

O portal de notícias Diário Online (Dol) faz parte do Grupo Rede Brasil Amazônica de Comunicação RBA. Inicialmente, em 2003, foi criado o site Diário do Pará, com a proposta de apenas transpor as notícias do jornal impresso (SOUSA, 2008). Em 2010, o site dá lugar ao portal de notícias Dol (SARGES; SOARES, 2016) com uma maior quantidade de conteúdos e serviços. O Diário Online possui perfis em outras plataformas digitais, como o Facebook (720 mil seguidores), o Twitter (84,1 milseguidores) e o Instagram (303 mil seguidores) . $^{3}$

O portal de notícias O Liberal integra o Grupo Liberal de Comunicação. A empresa é proprietária do diário mais antigo em circulação do estado do Pará - desde 1966, o jornal impresso de O Liberal (CASTRO; SEIXAS, 2013). Ele foi o primeiro periódico paraense a ter seu conteúdo jornalístico transposto para as plataformas digitais, a partir de 1997, por meio do site $O$ Liberal Online, que em 2004, se transformou em Portal ORM (SOUSA, 2008). Entretanto, em 2019, o Portal ORM deu lugar ao Portal OLIBERAL.com. 0 ciberjornal possui perfis em outras plataformas digitais, como o Facebook (511 mil seguidores), o Twitter (154,4 mil seguidores) e o Instagram (253 mil seguidores)4.

Adota-se, metodologicamente, a análise de conteúdo (CHIZZOTTI, 2000; BARDIN, 2006), com base em técnicas de abordagem qualitativa (FRAGOSO; RECUERO; AMARAL, 2011). As versões móveis dos portais jornalísticos foram avaliadas a partir de dez categorias: usabilidade, multimidialidade, hipertextualidade, participação, modelo de negócio, design responsivo, tactilidade, nivelabilidade,

\footnotetext{
${ }^{1}$ Disponivel em: https://dol.com.br/ Acesso em: 20 nov. 2021.

2 Disponivel em: https://oliberal.com/ Acesso em: 20 nov. 2021.

${ }^{3}$ Dados coletados em novembro de 2021.

${ }^{4}$ Dados coletados em novembro de 2021.
} 


\section{Brazilian \\ Creative Industries}

personalização e multisuporte. A análise foi realizada em julho de 2020, a partir do acesso aos portais por meio de smartphones com sistemas operacionais iOS e android.

\section{A RELAÇÃO ENTRE INDÚSTRIA CRIATIVA, JORNALISMO E SMARTPHONES}

O termo indústria criativa (IC) surgiu nos anos 1990, para designar setores que têm a criatividade como dimensão essencial (BENDASSOLLI et al., 2009). Desde então, são apontadas relações entre a IC e a comunicação. Segundo Feitosa e Belochio (2018), são quatro as relações principais: 1) Comunicação e Indústria Criativa como o domínio do "saber-fazer" e do "saber sobre o fazer"; 2) Indústria Criativa como objeto de estudo da Comunicação; 3) Indústria Criativa: em que se distingue e se relaciona com o conceito clássico de Indústria Cultural?; 4) Indústria Criativa e o escopo das teorias da comunicação. Feil e Guindani (2018), por sua vez, entendem a comunicação tanto como indústria criativa quanto como uma atividade voltada para a mesma.

De acordo com o Relatório sobre Economia Criativa (2002-2015)' , há uma simbiose entre os mundos criativo e digital. Nesse sentido, vale destacar que foi na década de 1990 também que teve início, de fato, a produção, a circulação e o consumo de produtos jornalísticos em ambientes digitais. Em um cenário de convergência jornalística (BARBOSA, 2009; KOLODZY, 2009; SALAVERRÍA; AVILÉS; MASIP, 2010), as tradicionais empresas noticiosas que construíram sua identidade e credibilidade em trajetória associada à publicação em papel, se adaptam e investem em outros produtos para conquistar novos públicos e manter o antigo, concomitantemente.

Assim, os vínculos estabelecidos historicamente entre jornais impressos e público, que são operacionalizados por contratos de comunicação (CHARAUDEAU, 2007), se deslocam para outros suportes na medida em que seus produtos são disponibilizados em plataformas digitais (GRUSZYNSKI, 2012). Há, portanto, uma ampliação, uma alteração e um redimensionamento desses contratos, que passam a ter especificidades em relação a cada uma das plataformas utilizadas (BELOCHIO, 2012; GRUSZYNSKI; LINDEMANN; OLIVEIRA, 2014).

Esse cenário, segundo Belochio e Feitosa (2018, p. 191), "vem mostrando reflexos no desenvolvimento de estratégias comunicacionais relacionadas à indústria criativa". Por conseguinte, com a crescente utilização de dispositivos móveis a produção criativa ganha possibilidades distintas "que potencializam atividades tradicionais da indústria criativa, ou mesmo resultam em novas produções

\footnotetext{
${ }_{5}^{5}$ Relatório sobre Economia Criativa (2002-2015) da UNCTAD: um resumo. Disponivel em: http://recbrasil.com.br/2021/01/ relatorio-sobre-economia-criativa-2002-2015-da-unctad-um-resumo/ Acesso em: 13 nov. 2021.
} 


\section{Brazilian \\ Creative Industries}

nos seus diferentes segmentos" (p. 197). Desse modo, entende-se que a chegada dos smartphones nas redações jornalísticas dão início a práticas inovadoras e criativas de produção, circulação e consumo de conteúdos em plataformas digitais (SOUSA, 2018).

Os dispositivos móveis são artefatos dotados de conectividade ubíqua e concebidos para a portabilidade cotidiana (AGUADO; CASTELLET, 2013). Eles são considerados meta-dispositivos tecnológicos por oferecerem funcionalidades como câmera, agenda, computador reprodutor de áudio e de vídeo, dentre outros. Assim, a "[...] plataforma móvel surge como uma espécie de terra prometida em que o consumo cultural não possui limitações contextuais: 'o que você quiser, sempre que quiser, onde quiser"'. (AGUADO; MARTíNEZ, 2008, p. 187, tradução nossa). Os smartphones favorecem o imediatismo (AGUADO; CASTELLET, 2013), o consumo de notícias ocorre a qualquer instante, sendo criado um "[...] cordão umbilical, permanentemente, entre quem informa e é informado." (FIDALGO; CANAVILHAS, 2009, p. 15). Eles também possibilitam uma maior portabilidade, podendo ser colocados no bolso da calça ou na bolsa e servindo, principalmente, à conversação (BARBOSA; SEIXAS, 2013), havendo, consequentemente, uma relação mais próxima do suporte com o leitor (CANAVILHAS, 2013). Esses dispositivos são considerados a quarta tela para consumo de conteúdos de cunho cultural e comunicacional. Os primeiros são o cinema, a televisão e o computador pessoal (AGUADO; MARTíNEZ, 200b). Inicialmente, a interação do público com esses suportes se dava pelo toque na tela. Mais tarde, começa a ganhar espaço também a interação por meio da voz (CANAVILHAS, 2021).

Os smartphones possuem funcionalidades específicas, tais como: a tactilidade (PALACIOS; CUNHA, 2012) ou o toque na tela (PAULINO, 2013) referente à interação por meio da interface que é tátil devido à tela touch screen; a nivelabilidade (PALACIOS et al., 2015) relacionada à orientação dupla (PAULINO, 2013) que permite a leitura tanto na horizontal quanto na vertical; a opticabilidade (PALACIOS et al., 2015) indicativa ao uso da câmera desses suportes que possibilita a interação do usuário com a interface através do código QR (Quick Response), da realidade aumentada e também da realidade virtual; a locabilidade (PALACIOS et al., 2015) alusiva à possibilidade que esses aparelhos têm de ter acesso a dados de localização devido às tecnologias de satélite, como o GPS.

Desse modo, os produtos desenvolvidos para smartphones podem ter "novas propriedades na sua interface e em seu hardware que potencializam interações com especificidades que vão além das características da produção para a web ou para a mídia impressa, estabelecendo assim novas semânticas." (PALACIOS et al., 2015, p. 7).

Oliveira (2017) afirma que embora os dispositivos móveis possuam características específicas que estimulam narrativas mais criativas e contextualizadas, é prematuro afirmar que neles haja uma transformação de formatos e gêneros jornalísticos. Já Empinotti (2020) explica que há uma tendência 


\section{Brazilian \\ Creative Industries}

de subutilização das funcionalidades dos dispositivos. De modo semelhante, Alexandre (2021) observa que grande parcela dos aplicativos jornalísticos investe na transposição ou adaptação do conteúdo, demonstrando que ainda há muito a ser explorado.

\section{PROCEDIMENTOS METODOLÓGICOS}

Para identificar, com foco na indústria criativa, de que forma os portais jornalísticos - Diário Online (Dol)e O Liberal - têm produzido conteúdos para os smartphones, recorre-se, metodologicamente, à análise de conteúdo que é uma ferramenta composta por um conjunto de técnicas de análise, com objetivo de enriquecer a leitura dos dados coletados a partir de uma abordagem qualitativa (CHIZZOTTI, 2000). Esta análise se fundamenta nas conceituações de Bardin (2006), a qual indica a execução de três fases na pesquisa: pré-análise (realizada em acessos prévios aos portais); exploração do material e tratamento dos resultados (construção da tabela informativa); inferência e interpretação (análise das categorias).

A abordagem qualitativa é responsável, segundo Fragoso, Recuero e Amaral (2011), por observar, contextualizar e analisar os fenômenos, levando em conta o seu caráter dinâmico. A quantidade de componentes da amostra é irrelevante, diante da importância da qualidade e aprofundamento da análise. Observa-se que os elementos podem ser escolhidos aleatoriamente, de acordo com as características do objeto de pesquisa.

Para alcançar o objetivo desta pesquisa, a partir do material investigado (coletado em julho de 2020) foram criadas dez categorias de análise com base em Palacios e Cunha (2012), Paulino (2013), Palacios et al. (2015), Gruszynski e Sanseverino (2017), Negreira e López (2017) e Silveira (2017). São elas: usabilidade, multimidialidade, hipertextualidade, participação, modelo de negócio, design responsivo, tactilidade, nivelabilidade, personalização e multisuporte.

As primeiras cinco categorias - usabilidade, multimidialidade, hipertextualidade, participação e modelo de negócio - têm como base definições de Negreira e López (2017). 0 primeiro critério usabilidade - envolve a análise da ampliação do texto e da foto, navegação dentro da seção e entre as seções. A multimidialidade - que é a segunda categoria - abrange o conteúdo adaptado com a utilização de galerias com vídeos e fotos, áudios, infografias, ilustrações. A terceira categoria - hipertextualidade é dividida entre links internos e externos. A participação - que é o quarto critério - envolve notificações, comentários, classificação da notícia, criação de conteúdo pelo usuário e possibilidades efetivas de contato. Já a quinta e última categoria com base em Negreira e López (2017), é o modelo de negócio, que está relacionado ao conteúdo ser grátis (com ou sem publicidade) ou pago. 


\section{Brazilian Creative Industries}

A categoria design responsivo tem base nas definições de Gruszynski e Sanseverino (2017) e se relaciona às adaptações de sites para as diferentes telas sem perda do conteúdo, o que pode evitar problemas de visualização e ampliar o público leitor. O conceito diz respeito à configuração de um layout fluido, que varia de acordo com o tamanho da tela do smartphone do usuário, com conteúdo flexível, acessível e de fácil visualização, independente do dispositivo móvel que for acessado.

A tactilidade (PALACIOS; CUNHA, 2012) - o toque na tela - que se refere à facilidade de interação por meio da interface que é tátil devido à tela touch screen e a nivelabilidade(PALACIOS et al., 2015) relacionada à dupla orientação (PAULINO, 2013), a qual permite a leitura do conteúdo tanto na horizontal quanto na vertical.

As duas últimas categorias de análise são definidas por Silveira(2017): personalização e multisuporte. A primeira - personalização - envolve as possibilidades de definição das preferências de leitura tanto por parte do usuário quanto as possibilidadesexploradas pelos portais de notícias. Já o multisuporte integra as múltiplas redes sociais digitais da empresa, tendo em vista um conteúdo circulante e não finito.

\section{ANÁLISE DOS PORTAIS}

Com o objetivo de facilitar a identificação de cada elemento que será analisado na versão móvel dos portais de notícias Dol e $O$ Liberal, foi contruida uma tabela composta pelas dez categorias e suas peculiaridades, que tem como base os dados coletados e analisados (Tabela 1). Observa-se que uma categorização pode perpassar a outra, por conta da integração das características que as compõem. 


\section{Brazilian Creative Industries}

\begin{tabular}{|c|c|c|c|c|c|}
\hline \multirow{2}{*}{ Categorias } & \multirow{2}{*}{ Características } & \multicolumn{2}{|c|}{ Dol } & \multicolumn{2}{|c|}{ O Liberal } \\
\hline & & Sim & Não & Sim & Não \\
\hline \multirow{4}{*}{ Usabilidade } & Ampliação do texto & $\mathbf{x}$ & & $\mathbf{x}$ & \\
\hline & Ampliação da foto & $\mathbf{x}$ & & $\mathbf{x}$ & \\
\hline & Navegação dentro daseção & $\mathbf{x}$ & & $\mathbf{x}$ & \\
\hline & Navegação entre as seções & $\mathbf{x}$ & & $\mathbf{x}$ & \\
\hline \multirow{5}{*}{ Multimidialidade } & Galerias com fotos & $\mathbf{x}$ & & $\mathbf{x}$ & \\
\hline & Vídeos & $\mathbf{x}$ & & $\mathbf{x}$ & \\
\hline & Áudios & $\mathbf{x}$ & & $\mathbf{x}$ & \\
\hline & Infografias & & $\mathbf{x}$ & & $\mathbf{x}$ \\
\hline & Ilustrações & & $\mathbf{x}$ & & $\mathbf{x}$ \\
\hline \multirow{2}{*}{ Hipertextualidade } & Link externo & $\mathbf{x}$ & & $\mathbf{x}$ & \\
\hline & Link interno & $\mathbf{x}$ & & $\mathbf{x}$ & \\
\hline \multirow{5}{*}{ Participação } & Notificações & & $\mathbf{x}$ & $\mathbf{x}$ & \\
\hline & Comentários & $\mathbf{x}$ & & $\mathbf{x}$ & \\
\hline & Classificação da notícia & & $\mathbf{x}$ & & $\mathbf{x}$ \\
\hline & Conteúdo do usuário & $\mathbf{x}$ & & & $\mathbf{x}$ \\
\hline & Contato & $\mathbf{x}$ & & & $\mathbf{x}$ \\
\hline \multirow{3}{*}{ Modelo de negócio } & Conteúdo grátis com publicidade & $\mathbf{x}$ & & $\mathbf{x}$ & \\
\hline & Conteúdo grátis sem publicidade & & $\mathbf{x}$ & & $\mathbf{x}$ \\
\hline & Conteúdo pago & & $\mathbf{x}$ & $\mathbf{x}$ & \\
\hline Design responsivo & Visualização adaptável & & $\mathbf{x}$ & $\mathbf{x}$ & \\
\hline Tactilidade & Interação da interface & $\mathbf{x}$ & & $\mathbf{x}$ & \\
\hline Nivelabilidade & Dupla orientação & $\mathbf{x}$ & & $\mathbf{x}$ & \\
\hline \multirow{2}{*}{ Personalização } & Usuário & & $\mathbf{x}$ & & $\mathbf{x}$ \\
\hline & Conteúdo & $\mathbf{x}$ & & $\mathbf{x}$ & \\
\hline Multisuporte & Integra redes sociais digitais & $\mathbf{x}$ & & $\mathbf{x}$ & \\
\hline
\end{tabular}

Fonte: Elaboração própria. 


\section{Brazilian \\ Creative Industries}

Observando os critérios de usabilidade, é possivel notar que os portais de notícias Diário Online e O Liberal atendem às quatro características apresentadas, oferecendo as opções de ampliação de texto e foto, navegação entre seções e dentro delas. A ampliação dos dois elementos - texto e foto - nos portais analisados pode ser realizada por meio do touchscreen, a partir do posicionamento dos dedos no elemento a ser ampliado e a movimentação de alargamento da página, através do afastamento dos dedos.

Ressalta-se que no Diário Online, ao serem efetuados dois toquesrápidos na tela, a imagem ou o texto também apresentam a função de zoom, entretanto, de forma bastante limitada, com um leve aumento. Em O Liberal, essa segunda função não é possivel. Essas funções contribuem para o cumprimento do elemento acessibilidade, permitindo que o conteúdo seja consumido por diferentes tipos de leitores, que possuem ou não limitações.

A navegação dentro da mesma seção do portal O Liberalocorre de forma vertical,através do rolamento da página. Para ter acesso aos chapéus das seções é necessário clicar no menu principal, disponível na parte superior da página inicial do site. Outra opção identificada de acesso a notícias da mesma seção é após o término de cada matéria, onde o portal disponibiliza as quatro notícias mais lidas da seção que está sendo acessada. Elas são organizadas na forma horizontal e divididas de duas em duas, com manchete e foto. Já no Dol, ao clicar em um dos chapéus das seções organizados horizontalmente na parte superior da página ou no chapéu de determinada seção apresentado no menu disponível ao lado da logo do portal, também na área superior da página, são apresentadas as quatro principais notícias da seção em forma de galeria e o usuário deve arrastar o dedo em cimada notícia principal para a lateral e assim consegue ter acesso às três outras notícias. 


\section{Brazilian Creative Industries}

Figura 1: Print das notícias na mesma seção

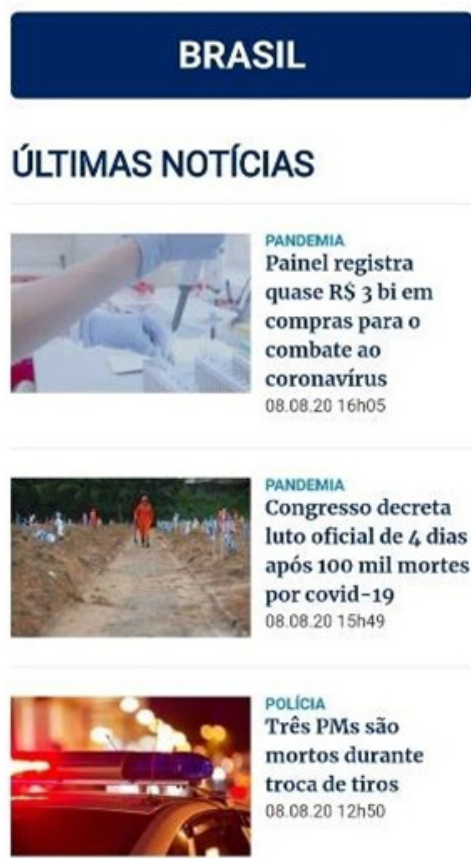

\section{Figura 2: Print da galeria da mesma seção}

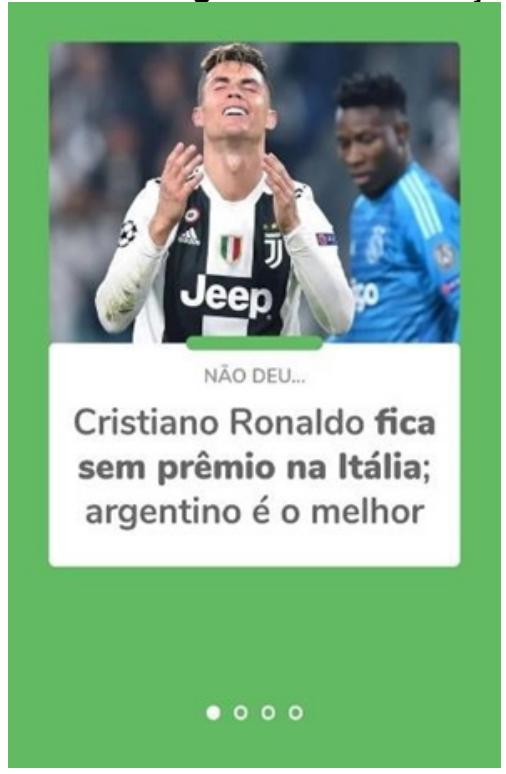

Fonte: Portal Dol

Fonte: Portal 0 Liberal

A navegação entre as seções pode ser realizada por meio do menu principal localizado na área superior esquerda dos dois portais. Nas páginas principais dos dois portais também é possível acessar os principais destaques de diferentes seções. Ao rolar a tela, eles estão apresentados verticalmente. É importante ressaltar que o portal Dol apresenta uma facilidade nesse tipo de navegação. Ao clicar em qualquer notícia, independente da seção, é possível continuar visualizando os chapéus das outras seções, organizados horizontalmente na parte superior da página. 


\section{Brazilian Creative Industries}

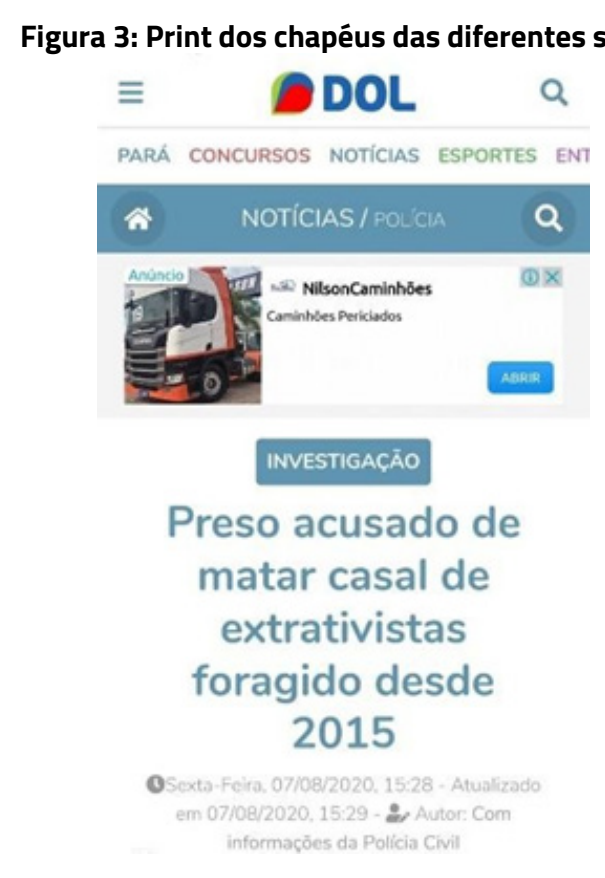

Fonte: Portal Dol

Pode-se observar no Dol que, independente da seção do conteúdo, os links para as demais seções seguem disponíveis na parte superior da tela. Assim, é possível acessar as outras seções, com apenas um clique. O portal O Liberal não possui essa opção.

Em relação à multimidialidade, os dois portais utilizam, com frequência, apenas três dos elementos: galerias com fotos, vídeos e áudios. Já infografias e ilustrações não fazem parte do dia a dia da produção jornalística para essas plataformas, tendo em vista que demandam mais tempo e consequentemente mais trabalho para os profissionais. É importante ressaltar que os dois veículos possuem conteúdos audiovisuais produzidos de forma específica para a plataforma. O Libplay, seção específica do portal O Liberal, possui 26 programas audiovisuais disponiveis para acesso. O portal Dol também possui uma aba com essa função, o Dolplay, com 17 programas disponiveis. Entretanto, não há atualização, o que compromete a eficiência da função. O programa "Dol agora", por exemplo, localizado dentro desta aba, que propõe a ideia de notícias quentes, foi atualizado, pela última vez, em 2018.

Sobre a função áudio é importante destacar que o Dol utiliza a ferramenta Audima, desenvolvida com base em inteligência artificial para converter conteúdos escritos em áudio, com o objetivo de gerar inclusão digital por meio do áudio, seja para pessoas com algum tipo de deficiência visual, analfabetas ou que preferem ouvir a ler um conteúdo. Todas as matérias do portal fazem uso dessa ferramenta. Já o portal $O$ Liberal não utiliza nenhuma ferramenta deste tipo, de modo que as matérias não possuem 


\section{Brazilian Creative Industries}

áudio, o que não permite a inclusão do público elencado anteriormente. Entretanto, produz conteúdos específicos para o site: os podcasts. São oito programas de podcasts disponiveis: Amazônia Viva, Égua do babado, Fala, Abner!, Hora do rush, Momento suave, Tudo delas, Mobiliza, Conexão Mineral - com conteúdo especializado produzido para a plataforma.

Figura 4: Print com ferramenta de áudio

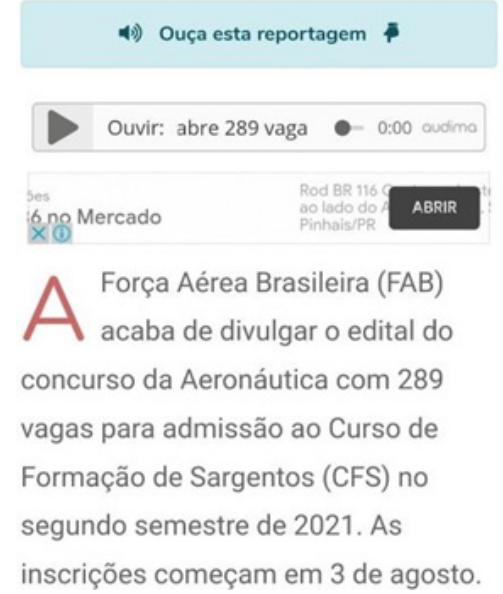

Fonte: Portal Dol
Figura 5: Podcast Mobiliza

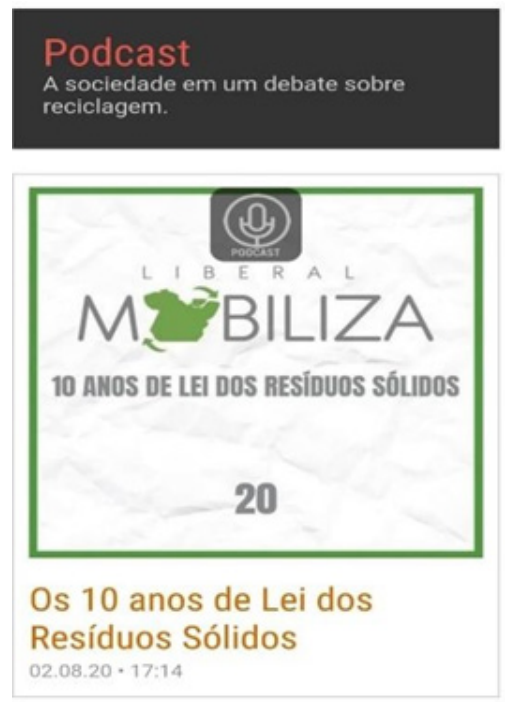

Fonte: Portal 0 Liberal

O critério da hipertextualidade é utilizado pelos dois portais por meio de links internos e externos. Apesar de algumas matérias criarem hiperlinks que direcionam o usuário para sites externos, deve-se ressaltar que os links internos são muito mais utilizados por ambos os sites. Na maioria das vezes, são links de matérias já publicadas pelos veículos. Nos dois portais, esses links, são apresentados, geralmente, no meio de uma notícia.

No Dol, no final de cada matéria, há um link com conteúdo relacionado e abaixo inúmeras chamadas de matérias, compostas por manchete e foto, que não estão necessariamente relacionadas ao conteúdo abordado. Identifica-se ainda, que entre essas chamadas, há matérias publicitárias com a identificação "Patrocinado". O Dol utiliza a plataforma Taboola Feed, que possui a função de exibir recomendações de conteúdo a partir do uso de algoritmos.

O portal O Liberal, que além dos hiperlinks utilizados no meio da matéria com conteúdos relacionados, também utiliza um hiperlink específico do Twitter da empresa com a frase "Siga o nosso perfil e fique por dentro das principais notícias no Pará, Brasil e Mundo" na mesma localização. Após a matéria, são apresentadas quatro notícias (formato horizontal) mais lidas da seção que está aberta e em seguida são 


\section{Brazilian \\ Creative Industries}

exibidos links relacionados, recomendados pela plataforma Outbrain, concorrente da Taboola Feed. Essa ferramenta também utiliza algoritmos e faz indicações com base na forma de como o usuário interage com o conteúdo publicado.

Em relação aos critérios de participação, inicia-se pela característica da notificação. Assim que o usuário acessa o portal de O Liberal, aparece uma notificação coma pergunta "Oliberal.com gostaria de enviar notificações das principais notícias para você". O usuário pode permitir ou não. Esse tipo de alerta não é utilizado pelo Dol.

Em relação às caixas de comentários, é importante frisar que os dois portais possuem um espaço destinado para este tipo de interação, entretanto, no Dol, é necessário um cadastro para que o comentário seja publicado, com o preenchimento do nome e e-mail, além da concordância com os termos de uso e política de privacidade da plataforma. Já em O Liberal, é necessário que o usuário faça login com o seu perfil de Facebook para que consiga efetivar o comentário. Entretanto, quem não possui conta nessa rede social digital, não pode interagir com o conteúdo, de forma que restringe a utilização desta função.

O recurso de classificação da notícia não é oferecido por nenhum dos dois portais. Deste modo, o leitor não tem a opção de curtir ou favoritar as notícias, ou seja, não tem a possibilidade de aceitar ou rejeitar um conteúdo de acordo com seu interesse. A forma deinteratividade com uma notícia em particular é através dos comentários e da opção de compartilhamento. No Dol, um conteúdo pode ser compartilhado através do Facebook, Twitter, Pinterest ou Whatsapp. Em O Liberal, dentre essas opções, somenteo Pinterest não é uma possibilidade.

O único contato que é destacado na página inicial de $O$ Liberal é destinado para quem quer realizar a assinatura de $O$ Liberal Digital (jornal impresso digitalizado). Entretanto não há um contato em destaque para a participação do usuário. O link do número de Whatsapp disponibilizado pelo portal não recebe as mensagens enviadas e não há outro link visivel que possibilite esse tipo de interação e sugestões do usuário, através do próprio portal. Já no final da página inicial do portal Dol, há possibilidades de contato através do Fale Conosco, onde o usuário pode enviar uma mensagem para a empresa, comperguntas, sugestões, denúncias, reclamações. $O$ portal incentiva a participação do usuário também por meio da disponibilização de um número de Whatsapp em destaque com a proposta "Faça sua denúncia pelo WhatsApp do Diário e apareça no DOL!". O portal também garante a opção de adicionar um e-mail para receber newsletter.

Em relação ao modelo de negócio adotado pelos portais há distinções. O veículo Dol disponibiliza todos os seus conteúdos de forma gratuita com anúncios publicitários, inclusive, o usuário acessa, de forma integral, a edição digitalizada completa do jornal impresso. O Liberal também garante conteúdos gratuitos com propaganda, sem limites de acesso, entretanto, para acessar o jornal impresso digital, o usuário precisa realizar uma assinatura mensal. 


\section{Brazilian \\ Creative Industries}

Em relação aos anúncios, observa-se que perpassam por várias categorias, como modelo de negócio, usabilidade, tactilidade. Ao acessar o portal Dol, pelo menos três anúncios aparecem na tela inicial, o que sobrecarrega a página e dificulta o acesso às notícias. Inclusive o anúncio que se apresenta na área superior da página, mesmo após ser fechado, atrapalha o acesso ao menu principal. De modo que dificulta a navegação na plataforma. 0 portal de $O$ Liberal também apresenta anúncios, porém, de forma que não interfere na navegação e em menor quantidade.

Sobre a categoria design responsivo, o acesso via smartphone pelos portais é adaptável, quando no formato vertical. Essa categoria se relaciona com a nivelabilidade, tendo em vista que ao modificar a rotação do celular para a horizontal, o portal 0 Liberal continua com layout fluido. A página muda de orientação, mas o conteúdo continua preenchendo todo o tamanho da tela. O mesmo não ocorre no portal Dol, tendo em vista que ao modificar a orientação, o formato do conteúdo disponibilizado verticalmente, permanece igual, de modo que o conteúdo, quando na horizontal, não se adapta e preencha toda a tela. A edição digitalizada do impresso disponibilizada pelo veículo também não apresenta esse critério. Ao modificar a orientação, as páginas do jornal se transformam em miniaturas ilegíveis.

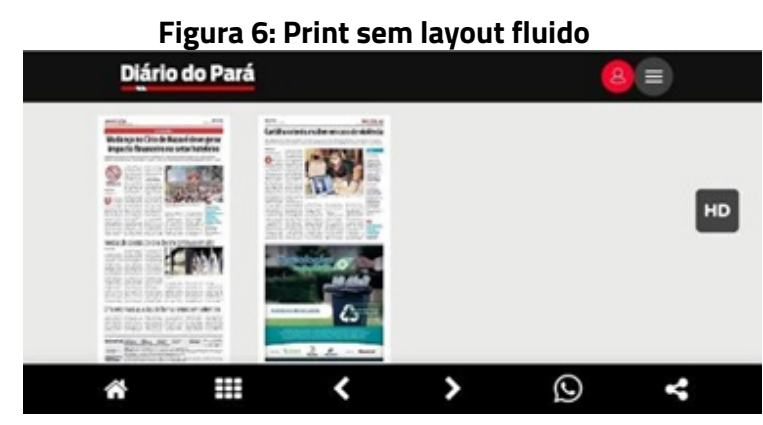

Fonte: Portal Dol
Figura 7: Print com layout fluido

MUTZOSI ÚUTIMAS MOBIIZA CONEXÃO MINERAL MAIS VALOR LBPLAY LIBLAB

$$
\text { PSC } 0 \times 0 \text { STC }
$$

Assista a todos os detalhes de Paysandu x Santa Cruz Partida marca a abertura da Série $\mathrm{C}$ do Brasileiro

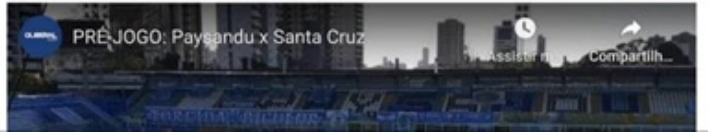

Fonte: Portal $\boldsymbol{O}$ Liberal

A categoria tactilidade é essencial para uma navegação efetiva nos portais. Nos dois portais, a utilização do touchscreen é, de modo geral, efetiva, pois permite a ampliação de fotos e textos, a movimentação de arrastar lateral, dentre outras possibilidades. Entretanto, é necessário observar que no $D o l$ os ícones para fechar os inúmeros anúncios que abrem no decorrer da navegação são pequenos e de difícil tactilidade, o que influencia na experiência do usuário. Já a navegação na edição digitalizada do jornal impresso do Dol proporciona uma experiência interessante para o usuário - no formato vertical do smartphone - que tem a opção de folhear as páginas, assim como a leitura do jornal no papel.

Em relação à nivelabilidade, como já abordado durante a análise do design responsivo, se faz presente nos dois portais. Ainda que o portal Do/não possua design responsivo sob a orientação horizontal, é possível realizar a leitura dos conteúdos. 0 Liberal permite, sem restrições, o uso dessa função. 


\section{Brazilian \\ Creative Industries}

Sobre a personalização dos conteúdos é importante destacar que o portal Dol utiliza diferentes cores para cada editoria, o que facilita a identificação das seções. Já o O Liberal, apesar de também definir cores por editorias apresentadas nos chapéus de cada notícia, no menu principal acessado pela parte superior do site, todas as seções são da cor azul marinho, que é a cor utilizada para todas as manchetes divulgadas, o que pode dificultar a orientação do usuário.

Em relação à personalização do usuário, os dois portais não possuem configurações específicas para que o consumidor informe as suas preferências de leitura, impedindo assim que o leitor escolha sobre quais temas deseja ser notificado ou tenha acesso, nem com que frequência.

O último critério de análise é o multisuporte que está relacionado às múltiplas redes sociais digitais utilizadas pelas empresas e à circulação de conteúdo ilimitado. O Dol, como citado na categoria de participação, disponibiliza ícones do Facebook, Twitter, Pinterest eWhatsapp, na área abaixo da manchete de todas as matérias publicadas, para que o usuáriocompartilhe o conteúdo. Os links para acesso aos perfis do jornal no Facebook, Twitter e Instagram estão disponibilizados no menu principal acessado através da parte superior do site. Já o portal O Liberal disponibiliza os links para compartilhamento dos conteúdos nas redes sociais digitais da mesma forma, entretanto, na parte inferior da manchete de cada matéria, o ícone do pinterest não se faz presente. Outra diferença é que no menu principal de $O$ Liberal, além dos links que constam no portal Dol, também estão os links para os perfis do jornal no Youtube e no Whatsapp.

\section{CONSIDERAÇÕES FINAIS}

O objetivo desta pesquisa foi identificar, com foco na indústria criativa, de que forma os portais jornalísticos - Diário Online (Dol) e O Liberal - têm produzido conteúdos para os smartphones. Com base na análise de conteúdo (CHIZZOTTI, 2000; BARDIN, 2006), os portais foram avaliados com base em dez categorias: usabilidade, multimidialidade, hipertextualidade, participação, modelo de negócio, design responsivo, tactilidade, nivelabilidade, personalização e multisuporte.

É possivel destacar alguns resultados obtidos por meio desta pesquisa. Ao mesmo tempo que o portal Dol disponibiliza alguns elementos que proporcionam maior facilidade e rapidez na navegação, como os chapéus organizados horizontalmente na áreasuperior da página, a quantidade de anúncios que surgem durante a navegação, sobrecarregam a página e atrapalham a experiência do usuário.

Destaca-se também a quantidade de programas audiovisuais produzidos pela seção específica do portal 0 Liberal - Libplay. São 26 programas disponíveis. Em contrapartida, em relação à multimidialidade, o Dol disponibiliza o conteúdo de todas as matérias em forma de áudio, através da ferramenta Audima, o 


\section{Brazilian

que possibilita a inclusão de pessoas com deficiência visual ou com esta preferência. $O$ Liberal não conta com essaestratégia.

Em relação à participação, sobre a característica comentário, apesar dos dois portais disponibilizarem essa função, há restrições na forma de acesso. Em O Liberal somente usuários do Facebook podem comentar, o que representa maior limitação do acesso aos usuários. Outro destaque é sobre o design responsivo dos portais, enquanto 0 Liberal apresenta layout fluido, o $\mathrm{Dol}$ não faz uso dessa adaptação quando a orientação muda para a horizontal.

Ressalta-se que nenhum dos portais possuem configurações específicas em relação à possibilidade de personalização do site pelo usuário. Por fim, destaca-se a possibilidade de envio de sugestão de conteúdo pelo usuário, que ocorre de forma mais acessível no Dol, tendo em vista o número do Whatsapp disponibilizado. Em $O$ Liberal o contato que é disponibilizado nãorecebe mensagens, comprometendo a interatividade do veículo.

Desse modo, em um cenário no qual os smartphones podem ser considerados como espaços inovadores para a produção de conteúdos pela indústria criativa, identificou-se que os dois principais jornais de tradição impressa da Amazônia Paraense têm produzido conteúdos para os smartphones sobretudo por meio dos portais noticiosos - Diário Online (Dol)e O Liberal - para o navegador (webmóvel) e dos perfis em redes sociais digitais.

Contudo, embora os portais jornalísticos analisados possuam muitos dos elementos avaliados nesta pesquisa, eles são produtos que não apresentam todas as potencialidades oferecidas pelos smartphones. Portanto, há aspectos subutilizados que precisam ser melhor explorados para serem considerados mais inovadores e criativos.

\section{REFERÊNCIAS}

AGUADO, Juan Miguel; CASTELLET, Andreu. Contenidos digitales en el entorno móvil: mapa de situación para marcas informativas y usuários. In: BARBOSA, Suzana; MIELNICZUK, Luciana. (Orgs.). Jornalismo e Tecnologias Móveis. Covilhã: Livros LabCOM, 2013.

AGUADO, Juan Miguel; MARTíNEZ, Immaculata J. La cuarta pantalla: industrias culturales y contenido móvil. In. AGUADO, Juan Miguel; MARTíNEZ, Immaculata (Orgs.). Sociedade móvil. Tecnología, identidad y cultura. Madrid: Biblioteca Nueva, 2008.

ALEXANDRE, Tássia Becker. Linguagem jornalística autóctone para dispositivos móveis. 2021. Tese (Doutorado em Ciências da Comunicação). Programa de Pós-Graduação em Ciências da Comunicação, Universidade do Vale do Rio dos Sinos, São Leopoldo, 2021. 


\section{Brazilian Creative Industries}

BARBOSA, Suzana. Convergência jornalística em curso: as iniciativas para integração de redações no Brasil. In: RODRIGUES, Carla (Org.). Jornalismo On- line: modos de fazer. Rio de Janeiro: Ed.PUC-Rio: Sulina, 2009. p. 35-55.

BARBOSA, Suzana; SEIXAS, Lia. Jornalismo e dispositivos móveis: percepções, usos e tendências. In: BARBOSA, Suzana; MIELNICZUK, Luciana. (Orgs.). Jornalismo e Tecnologias Móveis. Covilhã: Livros LabCOM, 2013.

BARDIN, Laurence. Análise de conteúdo. Lisboa: Edições 70, 2006.

BELOCHIO, Vivian de Carvalho. Jornalismo em contexto de convergência: implicações da distribuição multiplataforma na ampliação dos contratos de comunicação dos dispositivos de Zero Hora. 2012. Tese (Doutorado em Comunicação e Informação). Programa de Pós-Graduação em Comunicação e Informação, Universidade Federal do Rio Grande do Sul, Porto Alegre, 2012.

BELOCHIO, Vivian de Carvalho; FEITOSA, Sara Alves. A narrativa transmidiática como estratégia da indústria criativa: múltiplas apreensões dos objetos culturais em distintas plataformas e o caso da RBS TV. In: GUINDANI, Joel Felipe; SILVA, Marcela Guimarães (org.). Comunicação e indústria criativa: políticas, teorias e estratégias. Jaguarão, RS: CLAEC, 2018.

BENDASSOLLI, Pedro F.; WOOD JR., Thomaz; KIRSCHBAUM, Charles; PINA E CUNHA, Miguel. Indústrias criativas: definição, limites e possibilidades. RAE, São Paulo, v. 49, n.1, 2009.

CANAVILHAS, João. Modelos informativos para aparatos móviles: información hipermultimediática y Personalizada. In: MOLINA, Sonia González; CANAVILHAS, João; PRIETO, Miguel Carvajal; NORIEGA; Claudia Lerma; COBOS, Tania Cobos. (Orgs.). Hacia el Periodismo Móvil. Santiago de Chile: RMC/Cl, 2013.

CANAVILHAS, João. Epistemology of mobile journalism. A review. Profesional de la información, v. 30, n. $1,2021$.

CASTRO, Avelina; SEIXAS, Netília. História, discursos e relações de poder nas páginas de O Liberal. In: ENCONTRO NACIONAL DE HISTÓRIA DA MÍDIA - ALCAR, 9., 2013, Ouro Preto - MG. Anais... Ouro Preto, 2013.

CHARAUDEAU, Patrick. Discurso das mídias. São Paulo: Contexto, 2007.

CHIZZOTTI, Antonio. Pesquisa em ciências humanas e sociais. São Paulo: Cortez, 2000. 


\section{Brazilian Creative Industries}

EMPINOTTI, Marina Lisboa. Taxonomia para classificação de aplicativos noticiosos para smartphones. Um sistema baseado em funcionalidades e affordances. 2020. Tese (Doutorado em Estudos de Comunicação: Tecnologia, Cultura e Sociedade). Universidade da Beira Interior, Covilhã, 2020.

FRAGOSO, Suely; RECUERO, Raquel; AMARAL, Adriana. Métodos de pesquisa para internet. Porto Alegre: Sulina, 2011.

FEIL, Gabriel Sausen; GUINDANI, Joel Felipe. Comunicação como e comunicação para a indústria criativa. In. GUINDANI, Joel Felipe; SILVA, Marcela Guimarães (org.). Comunicação e indústria criativa: políticas, teorias e estratégias. Jaguarão, RS: CLAEC, 2018.

FEITOSA, Sara Alves; BELOCHIO, Vivian de Carvalho. Quatro relações entre Comunicação e Indústria Criativa. In. GUINDANI, Joel Felipe; SILVA, Marcela Guimarães (org.). Comunicação e indústria criativa: políticas, teorias e estratégias. Jaguarão, RS: CLAEC, 2018.

FIDALGO, Antonio; CANAVILHAS, João. Todos os jornais no bolso: pensando o jornalismo na era do celuIar. In: RODRIGUES, Carla (Org.). Jornalismo On-line: modos de fazer. Rio de Janeiro: Ed. PUC-Rio: Sulina, 2009.

GRUSZYNSKI, Ana. O papel do design no estabelecimento de contratos de leitura de jornais impressos: um estudo sobre a reforma gráfica de 2010 da Folha de S. Paulo (Brasil). Estudos em Comunicação, n. $12,2012$.

GRUSZYNSKI, Ana; LINDEMANN, Cristiane; OLIVEIRA, Cássia de. Virando-se por leitores: a reforma editorial e gráfica do jornal Zero Hora no cenário de convergência (2014). In: CONGRESSO BRASILEIRO DE CIÊNCIAS DA COMUNICAÇÃO - INTERCOM, 37., Foz do Iguaçu - PR, 2014. Anais... Foz do Iguaçu, 2014.

GRUSZYNSKI, Ana; SANSEVERINO, Gabriela. Design de jornais multiplataforma. CONGRESSO DA ASSOCIAÇÃO IBERO-AMERICANA DE PESQUISADORES DA COMUNICAÇÃO - IBERCOM, 15., Lisboa, Portugal, 2017. Anais... Lisboa, 2017.

KOLODZY, Janet. Convergence Explained. In: GRANT, August. E.; WILKINSON, Jeffrey. S. (Orgs.). Understanding Media Convergence. New York: Oxford University Press, 2009. p. 31-51.

NEGREIRA, Maria.; LÓPEZ, Xosé. Los cibermedios hiperlocales en el móvil. Análisis comparativo de seis apps españolas: grandes redes de medios frente a espacios de comunicaciónciudadana. In: CANAVILHAS, João; RODRIGUES, Catarina (org.). Jornalismo Móvel: Linguagem, géneros e modelos de negócio. Covilhã: LabCom, 2017. 


\section{Brazilian \\ Creative Industries}

OLIVEIRA, Vivian Rodrigues de. Jornalismo em dispositivos móveis: uma concepção estratégica de conteúdos noticiosos para tablets e smartphones. 2017. Tese (Doutorado em Comunicação). Programa de Pós-Graduação em Comunicação Social, Universidade de Brasília, Brasilia, 2017.

PALACIOS, Marcos Silva; CUNHA, Rodrigo do Espírito Santo da. A tactilidade em dispositivos móveis: primeiras reflexões e ensaio de tipologias. In: Contemporânea (UFBA. Online), v. 10, p. 668-685, 2012.

PALACIOS, Marcos; BARBOSA, Suzana; SILVA, Fernando; CUNHA, Rodrigo. Jornalismo móvel e inovações induzidas por affordances em narrativas para aplicativos em tablets e smartphones. In: CANAVILHAS, João; SATUF, Ivan. (Org.). Jornalismo para Dispositivos Móveis: produção, distribuição e consumo. 1. ed. Covilhã: Livros LabCom, 2015.

PAULINO, Rita. Conteúdo digital interativo para tablets-iPad: uma forma híbrida de conteúdo digital. In: PAULINO, Rita. ROGRIGUES, Vivian. (Orgs.). Jornalismo para tablets. Pesquisa e prática. Florianópolis: Insular, 2013.

SALAVERRÍA ALIAGA, Ramón; GARCIA AVILÉS, José Alberto; MASIP MASIP, Pere Masip. Concepto de convergencia periodística. In: LÓPEZ GARCIA, Xosé; PEREIRA FARIÑA, Xosé (Orgs.). Convergência Digital: Reconfiguración de los Medios de Comunicación en España. Santiago de Compostela: Universidade, Servizo de Publicacións e Intercambio Científico, 2010. p. 41-64.

SARGES, Letícia; SOARES, Rita. JORNALISMO NA WEB: O caso Toca Restô Bar pelo Diário Online (DOL). Revista de Comunicação e Cultura da Faculdade Estácio do Pará - Puçá, vol. 2, n. 2. ago../dez. 2016.

SILVEIRA, Stefanie Carlan da. Conteúdo jornalístico para smartphone: o formato da narrativa sistêmica no jornalismo ubíquo. 2017. Tese (Doutorado em Ciências da Comunicação). Programade Pós-Graduação em Ciências da Comunicação, Universidade de São Paulo, São Paulo, 2017.

SOUSA, Maíra de Cássia Evangelista de. Jornalismo digital no Pará: análise do Portal ORM, do Portal Cultura e do Diário do Pará. Trabalho de Conclusão de Curso (Graduação em Comunicação Social - Jornalismo). Faculdade de Comunicação, Universidade Federal do Pará, Belém, 2008.

SOUSA, Maíra de Cássia Evangelista de. Jornal e Mobilidade: Reconfigurações do Impresso ao Multiplataforma. 2018. Tese (Doutorado em Comunicação e Informação). Programa de Pós-Graduação em Comunicação e Informação, Universidade Federal do Rio Grande do Sul, Porto Alegre, 2018. 